\title{
Prevalence of suicide ideation and suicide attempts in nine countries
}

\author{
M. M. WEISSMAN, ${ }^{1}$ R. C. BLAND, G. J. CANINO, S. GREENWALD, H.-G. HWU, \\ P. R. JOYCE, E. G. KARAM, C.-K. LEE, J. LELLOUCH, J.-P. LEPINE, S. C. NEWMAN, \\ M. RUBIO-STIPEC, J. E. WELLS, P. J. WICKRAMARATNE, \\ H.-U. WITTCHEN AND E.-K. YEH
}

From the Department of Psychiatry, College of Physicians and Surgeons of Columbia University and Division of Clinical and Genetic Epidemiology, New York State Psychiatric Institute, New York, NY, USA; Department of Psychiatry, University of Alberta, Edmonton, Alberta, Canada; Behavioral Sciences Research Institute, University of Puerto Rico, San Juan, Puerto Rico; Department of Psychiatry, National Taiwan University Hospital and Department of Psychiatry, Taipei Medical College, Taipei, Taiwan; Department of Psychological Medicine and Department of Public Health and General Practice, Christchurch School of Medicine, Christchurch, New Zealand; Department of Psychiatry and Psychology, St. George Hospital, American University of Beirut, Lebanese University, St. Joseph University and Institute for Development of Research and Applied Care, Lebanon; Keyo Psychiatric Institute, Kyongii-Do, Republic of Korea; INSERM U 169, Villejuif and Hôpital Fernand Widal, Paris, France; and Max Planck Institute for Psychiatry, Clinical Institute, Munich, Germany

\begin{abstract}
Background. There are few cross-national comparisons of the rates of suicide ideation and attempts across diverse countries. Nine independently conducted epidemiological surveys using similar diagnostic assessment and criteria provided an opportunity to obtain that data.

Methods. Suicide ideation and attempts were assessed on the Diagnostic Interview Schedule in over 40000 subjects drawn from the United States, Canada, Puerto Rico, France, West Germany, Lebanon, Taiwan, Korea and New Zealand.

Results. The lifetime prevalence rates/100 for suicide ideation ranged from 2.09 (Beirut) to 18.51 (Christchurch, New Zealand). Lifetime prevalence rates/100 for suicide attempts ranged from 0.72 (Beirut) to 5.93 (Puerto Rico). Females as compared to males had only marginally higher rates of suicidal ideation in most countries, reaching a two-fold increase in Taiwan. Females as compared to males had more consistently higher rates for suicide attempts, reaching a two- to three-fold increase in most countries. Suicide ideation and attempts in most countries were associated with being currently divorced/separated as compared to currently married.

Conclusions. While the rates of suicide ideation varied widely by country, the rates of suicide attempts were more consistent across most countries. The variations were only partly explained by variation in rates of psychiatric disorders, divorce or separation among countries and are probably due to cultural features that we do not, as yet, understand.
\end{abstract}

\section{INTRODUCTION}

Although several published cross-national comparisons of the incidence and demographic risk

1 Address for correspondence: Dr Myrna M. Weissman, College of Physicians and Surgeons of Columbia University, Division of Clinical and Genetic Epidemiology, New York State Psychiatric Institute, 1051 Riverside Drive, Unit 24, New York, NY10032, USA. factors of completed suicide are available (Lester, 1994; Canetto \& Lester, 1995; Sartorius, 1995; Cantor et al. 1996; Pritchard, 1996; Yip, 1996), there are very few similar direct crossnational comparisons of rates of suicide ideation and attempts. The latest international study, the WHO/EURO multicentre study on parasuicide from 15 European centres, derived population estimates for parasuicide (defined as an act of 
deliberate self-harm) from figures of admissions to a wide range of health facilities where parasuicide patients were likely to be treated in the year 1989. Average annual incidence across sites was 167 per 100000 for males and 222 per 100000 for females (Platt, 1992). Schmidke et al. (1996) found that the average suicide attempt rate for the years 1989 to 1992 in these centres was 193 per 100000 for females and 140 per 100000 for males for a male to female ratio of $1 \cdot 4: 1$. However, these were estimates from treated samples and probably underestimate the rates, since not all persons who make attempts are treated. Rates of suicide ideation and attempts based on community studies have been reported in samples of adults from individual countries (Paykel et al. 1974; Dyck et al. 1988; Moscicke et al. 1988; Madianos et al. 1993, Bronisch \& Wittchen, 1994) and youths (Smith \& Crawford, 1986; Harkavy-Friedman et al. 1987; Lewis et al. 1988; Dubow et al. 1989; Andrews \& Lewinsohn, 1992). The differing age ranges and lack of standardization to a population make direct comparisons between countries using published data difficult.

In this paper, we present direct comparisons of the rates of suicide ideation and attempts from community household surveys conducted in nine countries in the 1980 s using similar diagnostic assessment. We also include data from a 1990 community survey in the US using similar questions about suicide behaviour.

\section{METHOD}

\section{Description of studies}

A detailed description of the cross-national sites has been published (Weissman et al. 1996). Each site used the Diagnostic Interview Schedule, Version III (Robins et al. 1981, 1983) and the DSM-III (APA, 1980). The translation, modification and piloting of the DIS were made by the investigators in each country as appropriate and details on the translations plus the methodology are included in the references.

The data from the NIMH Epidemiological Catchment Area Study (ECA) (Robins \& Regier, 1991) derive from five US communities (New Haven, Connecticut; Baltimore, Maryland; St. Louis, Missouri; the Piedmont County region of North Carolina; Los Angeles, California). The
Edmonton Survey of Psychiatric Disorders (Bland et al. 1988; Orn et al. 1988) was conducted in the city of Edmonton, Alberta, Canada. The Puerto Rico Study of Psychiatric Disorders (Canino et al. 1987) included persons living in households throughout Puerto Rico, in addition to household members temporarily away and those in institutions. The French Study of Psychiatric Disorders (Lepine et al. 1989) was conducted in Savigny, a suburb of Paris. The Munich, Germany Follow-up Study (Wittchen et al. 1992) was a 7 year follow-up investigation of a stratified random general population sample drawn from the adult population of the former Federal Republic of Germany (West Germany) in 1974. The rates reported are from the 1981 phase-II follow-up. The Beirut War Events and Depression Study (Karam, 1992) was conducted in Lebanon in four communities with different exposures to acts of war-two communities within Beirut city (Ashrafieh and Ain Remmaneh) and two communities outside of Beirut proper (Kornet Shehwan and Bejjeh). The Taiwan Psychiatric Epidemiology Project (Hwu et al. 1989) sampled three population areas representing metropolitan Taipei, township and rural areas throughout Taiwan. The Korean Epidemiologic Study of Mental Disorders (Lee, $1990 a, b$ ) sampled persons in urban Seoul and scattered rural regions across the Republic of Korea. The Christchurch Psychiatric Epidemiology Study (Oakley-Brown et al. 1989; Wells et al. 1989) included adults living in Christchurch in the South Island of New Zealand, oversampling young females.

Previous publications of this cross-national data also included a sample from Florence, Italy (Faravelli et al. 1990), but are not presented here since data on suicide ideation and attempts were not available.

For comparison purposes, data are included from the National Comorbidity Survey (NCS) (Kessler et al. 1994), a representative sample of 8098 persons age 15-54 living in the 48 coterminous United States and conducted during 1990-1992. These data are considered separately as a different diagnostic assessment, the Composite International Diagnostic Interview (CIDI; WHO, 1990) was used, which makes DSMIII-R diagnoses (APA, 1987). To increase comparability with the ages in the other samples, we only include persons aged 18-54 $(N=7640)$ 
from this site. The response rates for all sites were over $70 \%$ with the exception of France, $63 \%$ (Weissman et al. 1996).

\section{Outcome variables}

Suicide ideation was assessed in the depression module of the DIS and the CIDI with the question 'Did you ever feel so low you thought of committing suicide?' and suicide attempts were operationalized with the question 'Have you ever attempted suicide?'. Gender and current marital status were also recorded.

\section{Sampling design and statistical analysis}

The ECA, Edmonton, Puerto Rico, and Christchurch were household probability samples; the remainder of the sites, except for West Germany, were drawn as simple random samples constructed so that each household member had the same probability of selection. Because of unequal selection probability of a respondent in the United States, Edmonton, Puerto Rico and Christchurch, a design weight was computed. For these sites drawn as random samples, the design weight was set at $1 \cdot 0$ for each respondent.

The stratification method used for the phaseII 1981 follow-up in West Germany included all subjects who had high scores on the clinical selfrating scales at the phase-I investigation in 1974, plus $40 \%$ of the sample who were randomly drawn from the subjects successfully interviewed in phase-I. The design weight for West Germany was computed by weighting back to the original 1974 sample by correcting for the proportion of high and low scorers in that sample (Wittchen et al. 1992).

The NCS was also a household probability sample and the data were weighted to the national population characteristics defined by the 1989 US National Health Interview Survey (USDHHS, 1992).

In order to make valid comparisons of rates across cross-national sites, the rates of suicide ideation and suicide attempts at each cross national site were standardized to the age and sex distribution of the 1980 US census according to methods described by Breslow \& Day (1987; Tables 1 and 2). The rates will differ from those reported in the ECA (Moscicke et al. 1988) because of the use of the restricted age group. Analyses are reported only for the 18 to 64 yearold group, with values for West Germany based on ages 26 to 64 . NCS data included ages 18-54 years as no one over age 54 was sampled; these data were weighted (as described above) but not standardized to the ECA. All weights were scaleweighted to the equivalent random sample size at each site (Potthoff et al. 1992).

The odds ratios for marital status in Table 3 were obtained from logistic regression, which included age categories and gender. These adjusted odds ratios differ slightly from the crude odds ratios which can be calculated from the prevalences in Tables 1 and 2 .

In addition, in order to control for the effects of confounding of other psychiatric disorders that are associated with suicide behaviour and vary by site (major depression, any anxiety disorder, alcohol or drug abuse/dependence, as well as marital status - separation or divorce), we also directly standardized the rates of suicide ideation and attempts to the ECA distribution of these factors, age and sex with the methods described above by Breslow \& Day (1987; Tables 4 and 5). Alcohol and drug abuse was not assessed in Savigny and Beirut. In addition, anxiety disorders were not assessed at Beirut. Beirut had only two persons who were divorced or separated in the sample which is too small for any meaningful analysis here. Only marital status is analysed for the NCS due to diagnostic methods that differed from the ECA and the rest of the cross-national sites.

\section{RESULTS}

\section{Suicide ideation}

The lifetime prevalence rate/100 for suicide ideation (Table 1) varied from 2.09 in Beirut, Lebanon to $18 \cdot 51$ in Christchurch, New Zealand. The rates are slightly higher in females than males in all sites. Most of the female-male differences, with the exception of Taiwan and Lebanon, are small with either no or borderline statistical significance.

Divorced or separated, as compared to currently or never married persons had the higher rates of suicide ideation in every site. These differences in rates were significant among marital groups at every site except Puerto Rico. Odds ratios measuring the association between suicide ideation and marital status adjusting for age and sex (Table 3) show that there is a two- 
Table 1. Lifetime rate of suicide ideation ${ }^{\mathrm{a}}$

\begin{tabular}{|c|c|c|c|c|c|c|c|c|}
\hline & \multicolumn{8}{|c|}{ Lifetime rate per 100 (s.E.) of suicide ideation } \\
\hline & \multirow[b]{2}{*}{ Overall } & \multicolumn{3}{|c|}{ Gender } & \multicolumn{4}{|c|}{ Marital status (at interview) } \\
\hline & & Males & Females & $\mathrm{F} / \mathrm{M}(95 \% \mathrm{CI})$ & Married & $\begin{array}{l}\text { Divorced/ } \\
\text { separated }\end{array}$ & $\begin{array}{l}\text { Never } \\
\text { married }\end{array}$ & $P$ \\
\hline \multicolumn{9}{|l|}{ United States } \\
\hline ECA $(1980 s)^{b}$ & $11 \cdot 18(0 \cdot 34)$ & $8 \cdot 87(0 \cdot 44)$ & $13 \cdot 30(0 \cdot 51)$ & $1.50(1.33-1.70)$ & $8 \cdot 64(0 \cdot 40)$ & $19 \cdot 57(1 \cdot 22)$ & $13 \cdot 05(0 \cdot 70)$ & $0 \cdot 001$ \\
\hline $\operatorname{NCS}(1990 \mathrm{~s})^{\mathrm{c}}$ & $16 \cdot 52(0 \cdot 60)$ & $14 \cdot 66(0 \cdot 81)$ & $18 \cdot 30(0 \cdot 87)$ & $1.25(1.08-1.44)$ & $13 \cdot 86(0 \cdot 71)$ & $23 \cdot 82(1 \cdot 91)$ & $19 \cdot 23(1 \cdot 28)$ & $0 \cdot 001$ \\
\hline Edmonton, Alberta & $11 \cdot 25(0 \cdot 64)$ & $9 \cdot 63(0 \cdot 87)$ & $12 \cdot 74(0 \cdot 94)$ & $1 \cdot 32(1 \cdot 05-1 \cdot 66)$ & $8 \cdot 24(0 \cdot 73)$ & $23 \cdot 72(2 \cdot 57)$ & $12 \cdot 80(1 \cdot 30)$ & $0 \cdot 001$ \\
\hline Puerto Rico & $9 \cdot 51(0 \cdot 84)$ & $8 \cdot 19(1 \cdot 14)$ & $10 \cdot 72(1 \cdot 23)$ & $1 \cdot 31(0 \cdot 92-1 \cdot 86)$ & $9 \cdot 42(1 \cdot 09)$ & $14 \cdot 00(3 \cdot 22)$ & $8.91(1 \cdot 54)$ & $0 \cdot 25$ \\
\hline Savigny, France & $14 \cdot 20(1 \cdot 10)$ & $11 \cdot 71(1 \cdot 46)$ & $16.49(1.62)$ & $1.41(1.03-1.92)$ & $11.96(0 \cdot 90)$ & $33 \cdot 15(4 \cdot 62)$ & $16 \cdot 30(2 \cdot 29)$ & $0 \cdot 001$ \\
\hline West Germany ${ }^{\mathrm{d}}$ & $15.62(1.89)$ & $14 \cdot 41(2 \cdot 65)$ & $16 \cdot 73(2 \cdot 69)$ & $1 \cdot 16(0 \cdot 72-1.87)$ & $11.02(1.85)$ & $40 \cdot 02(8 \cdot 29)$ & $31 \cdot 55(8 \cdot 10)$ & $0 \cdot 001$ \\
\hline Beirut, Lebanon & $2.09(0.68)$ & $1 \cdot 24(0.77)$ & $2 \cdot 88(1 \cdot 11)$ & $2.33(0.58-9 \cdot 32)$ & - e & - e & - e & \\
\hline Taiwan & $5 \cdot 28(0 \cdot 23)$ & $3 \cdot 30(0 \cdot 26)$ & $7 \cdot 10(0 \cdot 36)$ & $2 \cdot 15(1 \cdot 80-2 \cdot 58)$ & $4 \cdot 69(0 \cdot 25)$ & $8.40(1.47)$ & $6 \cdot 54(0.52)$ & 0.001 \\
\hline Korea & $16 \cdot 22(0 \cdot 53)$ & $14 \cdot 00(0 \cdot 72)$ & $18 \cdot 26(0 \cdot 77)$ & $1 \cdot 30(1 \cdot 14-1 \cdot 48)$ & $14 \cdot 29(0 \cdot 61)$ & $29 \cdot 82(7 \cdot 88)$ & $20 \cdot 06(1 \cdot 18)$ & $0 \cdot 001$ \\
\hline $\begin{array}{l}\text { Christchurch, } \\
\text { New Zealand }\end{array}$ & $18 \cdot 51(1 \cdot 17)$ & $14 \cdot 88(1 \cdot 54)$ & $21 \cdot 85(1 \cdot 72)$ & $1.47(1.41-1.89)$ & $13.69(1.32)$ & $35 \cdot 59(4 \cdot 70)$ & $23 \cdot 36(2 \cdot 44)$ & $0 \cdot 001$ \\
\hline
\end{tabular}

a Ages 18-64, standardized to the US 1980 census by age and sex.

b Epidemiologic Catchment Area study.

c National Comorbidity Study, ages 18-54; weighted to 1989 US NHIS.

d Ages 26-64.

e Prevalence not estimated due to small number of observations in each marital group.

Table 2. Lifetime rate of suicide ideation ${ }^{\mathrm{a}}$

\begin{tabular}{|c|c|c|c|c|c|c|c|c|}
\hline & \multicolumn{8}{|c|}{ Lifetime rate per 100 (S.E.) of suicide attempts } \\
\hline & Overall & \multicolumn{3}{|c|}{ Gender } & \multicolumn{4}{|c|}{ Marital status (at interview) } \\
\hline \multicolumn{9}{|l|}{ United States } \\
\hline Edmonton, Alberta & $3 \cdot 82(0 \cdot 39)$ & $1 \cdot 88(0 \cdot 40)$ & $5 \cdot 61(0 \cdot 65)$ & $2.99(1.90-4.69)$ & $2 \cdot 42(0 \cdot 41)$ & $9 \cdot 68(1 \cdot 79)$ & $4 \cdot 31(0 \cdot 79)$ & $0 \cdot 001$ \\
\hline Puerto Rico & $5.93(0.68)$ & $4 \cdot 75(0 \cdot 68)$ & $7.02(1.02)$ & $1 \cdot 48(0 \cdot 93-2 \cdot 34)$ & $5 \cdot 26(0 \cdot 84)$ & $8.44(2 \cdot 58)$ & $6 \cdot 77(0 \cdot 35)$ & $0 \cdot 32$ \\
\hline Savigny, France & $4.95(0 \cdot 95)$ & $2.70(0 \cdot 73)$ & $7 \cdot 02(1 \cdot 11)$ & $2 \cdot 60(1.44-4 \cdot 45)$ & $4 \cdot 46(0 \cdot 57)$ & $10 \cdot 58(3.02)$ & $5 \cdot 41(1.40)$ & $0 \cdot 02$ \\
\hline West Germany ${ }^{\mathrm{d}}$ & $3 \cdot 44(0 \cdot 95)$ & $2 \cdot 76(1 \cdot 24)$ & $4.06(1.42)$ & $1.47(0 \cdot 48-4 \cdot 45)$ & $2 \cdot 24(0 \cdot 87)$ & $16 \cdot 30(6 \cdot 25)$ & $1 \cdot 58(2 \cdot 17)$ & $0 \cdot 001$ \\
\hline Beirut, Lebanon & $0 \cdot 72(0 \cdot 40)$ & $0.52(0.50)$ & $0.90(0.63)$ & $1 \cdot 73(0 \cdot 17-17 \cdot 15)$ & - e & - e & - e & \\
\hline Taiwan & $0.75(0.09)$ & $0.39(0.09)$ & $1.08(0 \cdot 14)$ & $2.77(1.67-4.59)$ & $0 \cdot 71(0 \cdot 98)$ & $1 \cdot 36(0 \cdot 61)$ & $0 \cdot 81(0 \cdot 19)$ & $0 \cdot 37$ \\
\hline
\end{tabular}

a Ages 18-64, standardized to the US 1980 census by age and sex.

b Epidemiologic Catchment Area study.

c National Comorbidity Study, ages 18-54; weighted to 1989 US NHIS.

d Ages 26-64.

e Prevalence not estimated due to small number of observations in each marital group.

to more than four-fold statistically significant increase in risk for suicide ideation among those divorced or separated compared to married in every site except for Puerto Rico. The associations are weaker for never married compared to married.

\section{Suicide attempts}

The lifetime prevalence rates/100 for suicide attempts (Table 2) were relatively consistent across sites. With the exception of low rates from Beirut and Taiwan $(0.72$ and 0.75 , re- 
Table 3. Association between suicide ideation, suicide attempts and marital status (odds ratio and $95 \%$ confidence intervals)

\begin{tabular}{|c|c|c|c|c|}
\hline & \multicolumn{2}{|c|}{ Suicide ideation } & \multicolumn{2}{|c|}{ Suicide attempt } \\
\hline & $\begin{array}{c}\text { Divorced/separated } \\
v . \text { married }\end{array}$ & $\begin{array}{c}\text { Never married } \\
\text { v. married }\end{array}$ & $\begin{array}{c}\text { Divorced/separated } \\
v . \text { married }\end{array}$ & $\begin{array}{c}\text { Never married } \\
v . \text { married }\end{array}$ \\
\hline \multicolumn{5}{|l|}{ United States } \\
\hline ECA (1980s) & $2 \cdot 44(2 \cdot 03-2 \cdot 93)$ & $1 \cdot 27(1.06-1 \cdot 53)$ & $3.64(2 \cdot 70-4.91)$ & $1 \cdot 12(0 \cdot 79-1 \cdot 58)$ \\
\hline NCS (1990s) & $1.90(1.50-2 \cdot 41)$ & $1.38(1.09-1.75)$ & $2 \cdot 67(1.85-3 \cdot 85)$ & $1.03(0.67-1.57)$ \\
\hline Edmonton, Alberta & $3 \cdot 66(2 \cdot 60-5 \cdot 15)$ & $1.30(0.92-1.84)$ & $4 \cdot 89(2 \cdot 86-8 \cdot 34)$ & $1.53(0 \cdot 84-2 \cdot 75)$ \\
\hline Puerto Rico & $1.50(0.84-2.69)$ & $1.09(0.66-1.80)$ & $1 \cdot 56(0 \cdot 75-3 \cdot 26)$ & $1.72(0.94-3 \cdot 13)$ \\
\hline Savigny, France & $3.65(2 \cdot 35-5 \cdot 68)$ & $1.43(0.99-2.07)$ & $2 \cdot 52(1 \cdot 29-4.99)$ & $1 \cdot 22(0 \cdot 67-2 \cdot 23)$ \\
\hline West Germany & $3.76(1.80-7 \cdot 85)$ & $3 \cdot 86(1 \cdot 79-8 \cdot 33)$ & $7 \cdot 14(2 \cdot 05-24 \cdot 80)$ & $0.58(0.03-10 \cdot 65)$ \\
\hline Taiwan & $1.97(1.31-2.98)$ & $1.24(0.96-1.59)$ & $2 \cdot 24(0 \cdot 83-6 \cdot 04)$ & $0 \cdot 87(0 \cdot 46-1 \cdot 66)$ \\
\hline Korea & $2 \cdot 55(1 \cdot 21-5 \cdot 38)$ & $1.30(1.03-1.64)$ & $2 \cdot 71(0 \cdot 72-10 \cdot 92)$ & $0 \cdot 75(0 \cdot 46-1 \cdot 23)$ \\
\hline Christchurch, New Zealand & $3 \cdot 38(2 \cdot 14-5 \cdot 36)$ & $1.98(1.24-2 \cdot 89)$ & $5 \cdot 69(2 \cdot 68-12 \cdot 05)$ & $2 \cdot 46(1 \cdot 07-5 \cdot 65)$ \\
\hline
\end{tabular}

Table 4. Suicide ideation in cross-national samples standardized to rates in the United States, $1980^{\mathrm{a}}$

\begin{tabular}{|c|c|c|c|c|c|}
\hline & \multicolumn{5}{|c|}{ Rate $/ 100$, (S.E.), standardized by } \\
\hline & Age and sex & $\begin{array}{l}\text { Major depression, } \\
\text { age and sex }\end{array}$ & $\begin{array}{l}\text { Any anxiety, } \\
\text { age and sex }\end{array}$ & $\begin{array}{l}\text { Alcohol/drug } \\
\text { age and sex }\end{array}$ & $\begin{array}{c}\text { Separation/divorce, } \\
\text { age and sex }\end{array}$ \\
\hline \multicolumn{6}{|l|}{ United States } \\
\hline ECA $(1980 s)^{c}$ & $11 \cdot 18(0 \cdot 34)$ & $11 \cdot 18(0 \cdot 34)$ & $11 \cdot 18(0 \cdot 34)$ & $11 \cdot 18(0 \cdot 34)$ & $11 \cdot 18(0 \cdot 34)$ \\
\hline $\operatorname{NCS}(1990 \mathrm{~s})^{\mathrm{d}}$ & $16 \cdot 52(0 \cdot 60)$ & $\mathrm{e}^{\mathrm{e}}$ & - e & - e & $16 \cdot 84(0 \cdot 62)$ \\
\hline Edmonton, Alberta & $11 \cdot 25(0 \cdot 64)$ & $9 \cdot 70(0 \cdot 61)$ & $12 \cdot 09(0 \cdot 67)$ & $10 \cdot 93(0 \cdot 64)$ & $11 \cdot 46(0 \cdot 65)$ \\
\hline Puerto Rico & $9 \cdot 51(0 \cdot 84)$ & $10 \cdot 06(0 \cdot 87)$ & $9 \cdot 94(0 \cdot 87)$ & $10 \cdot 59(0.98)$ & $9 \cdot 64(0 \cdot 85)$ \\
\hline Savigny, France & $14 \cdot 20(1 \cdot 10)$ & $10 \cdot 19(1 \cdot 00)$ & $13 \cdot 03(1 \cdot 19)$ & $-\mathrm{f}$ & $15 \cdot 42(1 \cdot 17)$ \\
\hline West Germany ${ }^{g}$ & $15.62(1.89)$ & $14 \cdot 13(1 \cdot 83)$ & $16.41(1.94)$ & $15.94(1.94)$ & $17 \cdot 22(2 \cdot 04)$ \\
\hline Beirut, Lebanon & $2.09(0 \cdot 68)$ & $1.57(0.73)$ & $-{ }^{\mathrm{f}}$ & $-\mathrm{f}^{\mathrm{r}}$ & $-{ }^{\mathrm{h}}$ \\
\hline Taiwan & $5 \cdot 28(0 \cdot 23)$ & $7 \cdot 07(0 \cdot 28)$ & $6 \cdot 43(0 \cdot 27)$ & $6.68(0 \cdot 34)$ & $6 \cdot 32(0 \cdot 35)$ \\
\hline Korea & $16 \cdot 22(0 \cdot 53)$ & $17 \cdot 30(0 \cdot 55)$ & $17 \cdot 93(0 \cdot 59)$ & $16 \cdot 83(0 \cdot 60)$ & $17 \cdot 45(0 \cdot 88)$ \\
\hline Christchurch, New Zealand & $18 \cdot 51(1 \cdot 17)$ & $15 \cdot 75(1 \cdot 12)$ & $19 \cdot 10(1 \cdot 20)$ & $15 \cdot 34(1 \cdot 17)$ & $19 \cdot 06(1 \cdot 18)$ \\
\hline
\end{tabular}

a Ages 18-64.

b Rates of abuse or dependence.

${ }^{c}$ Epidemiologic Catchment Area study.

d National Comorbidity Study, ages 18-54.

e Depression, anxiety and substance abuse not considered due to different diagnostic methods from the other sites.

Not assessed.

g Ages 26-64.

${ }^{\mathrm{h}}$ Not considered due to small number of persons.

spectively), the prevalence ranges from 3.13 in the ECA to 5.93 in Puerto Rico. There was a significant two- to three-fold increase in risk for females compared to males in the ECA, NCS, Edmonton, Savigny, Taiwan and Christchurch but not in Puerto Rico, West Germany, Beirut or Korea. Rates by marital status show similar patterns of prevalence and risk as that of suicide ideation. Persons divorced or separated, as compared to those currently or never married, had higher rates of suicide attempts in every site. Odds ratios (Table 3 ) show that there is a two- to more than seven-fold statistically significant increase in risk in divorced/separated compared to married in the ECA, NCS, Edmonton, Savigny, West Germany and Christchurch. There are no significant associations for never married compared to married except for Christchurch $(\mathrm{OR}=2 \cdot 46,95 \%$ CI 1·07-5.04).

\section{Comparison between the ECA and NCS}

The difference in rates of suicide behaviour between (ECA) 1980s; and (NCS) 1990s; when the two United States surveys were conducted 
Table 5. Suicide attempts in cross-national samples standardized to different distributions of the United States, $1980^{\mathrm{a}}$

\begin{tabular}{|c|c|c|c|c|c|}
\hline & \multicolumn{5}{|c|}{ Rate $/ 100$, (S.E.), standardized by } \\
\hline & Age and sex & $\begin{array}{l}\text { Major depression, } \\
\text { age and sex }\end{array}$ & $\begin{array}{l}\text { Any anxiety, } \\
\text { age and sex }\end{array}$ & $\begin{array}{l}\text { Alcohol/drug } \\
\text { age and sex }\end{array}$ & $\begin{array}{c}\text { Separation/divorce, } \\
\text { age and sex }\end{array}$ \\
\hline \multicolumn{6}{|l|}{ United States } \\
\hline ECA $(1980 s)^{c}$ & $3 \cdot 13(0 \cdot 19)$ & $3 \cdot 13(0 \cdot 19)$ & $3 \cdot 13(0 \cdot 19)$ & $3 \cdot 13(0 \cdot 19)$ & $3 \cdot 13(0 \cdot 19)$ \\
\hline $\operatorname{NCS}(1990 \mathrm{~s})^{\mathrm{d}}$ & $4 \cdot 84(0 \cdot 34)$ & - e & - e & $-\mathrm{e}$ & $5.03(0 \cdot 19)$ \\
\hline Edmonton, Alberta & $3 \cdot 82(0 \cdot 39)$ & $3 \cdot 12(0 \cdot 36)$ & $4 \cdot 33(0 \cdot 42)$ & $3 \cdot 76(0 \cdot 39)$ & $3.97(0 \cdot 40)$ \\
\hline Puerto Rico & $5.93(0.68)$ & $6.08(0.69)$ & $6 \cdot 38(0 \cdot 71)$ & $7 \cdot 05(0 \cdot 82)$ & $6 \cdot 00(0 \cdot 69)$ \\
\hline Savigny, France & $4.95(0 \cdot 95)$ & $3 \cdot 27(0 \cdot 59)$ & $4 \cdot 23(0 \cdot 65)$ & $-\mathrm{f}$ & $5 \cdot 24(0 \cdot 72)$ \\
\hline West Germany ${ }^{\mathrm{g}}$ & $3.44(0.95)$ & $3.08(0.91)$ & $3.39(0.95)$ & $3 \cdot 50(0 \cdot 97)$ & $3.91(1.05)$ \\
\hline Beirut, Lebanon & $0 \cdot 72(0 \cdot 40)$ & $0.29(0 \cdot 32)$ & $-\mathrm{f}$ & $-\mathrm{f}$ & $\mathrm{C}^{\mathrm{h}}$ \\
\hline Taiwan & $0.75(0.09)$ & $1 \cdot 32(0 \cdot 12)$ & $1 \cdot 22(0 \cdot 12)$ & $1.92(0 \cdot 19)$ & $0 \cdot 86(0 \cdot 13)$ \\
\hline Korea & $3 \cdot 20(0 \cdot 25)$ & $3 \cdot 81(0 \cdot 28)$ & $3 \cdot 80(0 \cdot 29)$ & $3.69(0 \cdot 30)$ & $3.45(0.42)$ \\
\hline Christchurch, New Zealand & $4.43(0 \cdot 62)$ & $3.56(0.57)$ & $4 \cdot 75(0 \cdot 65)$ & $4 \cdot 35(0 \cdot 62)$ & $4.82(0.64)$ \\
\hline
\end{tabular}

a Ages 18-64.

${ }^{b}$ Rates of abuse or dependence.

c Epidemiologic Catchment Area study.

d National Comorbidity Study, ages 18-54.

e Depression, anxiety and substance abuse not considered due to different diagnostic methods from the other sites.

${ }^{i}$ Not assessed.

g Ages 26-64.

h Not considered due to small number of persons.

were compared. In this analysis, the age range of the ECA was further restricted to 18-54 years to match the age range used for the NCS. Even when using identical age ranges in the two surveys, the rates were still significantly higher in the NCS (1990) compared with the ECA (1980) for suicide ideation $(16 \cdot 52$ v. $12 \cdot 10, Z=6 \cdot 42$, $P<0.01)$ and for suicide attempts $(4.84$ v. 3.42 , $Z=3.61, P<0.01)$. The sex ratios and odds ratios for marital status also did not change substantially with the restricted age range of the ECA.

\section{Effects of different rates of psychiatric disorder}

To determine whether the different rates of major depression, any anxiety disorder, alcohol or drug abuse/dependence and separation or divorce among countries might explain the differing rates of suicidal behaviour, we standardized the rates of suicide ideation and attempts in each country to the distribution of these factors (and age and sex) in the ECA (Tables 4 and 5). In general, standardizing has only modest effects on rates. While adjustment often decreases from the US rates (e.g. all rates from Taiwan are closer after adjustment as are Christchurch rates adjusted for depression or alcohol/drug disorder), adjustment sometimes exaggerates differences (e.g. Korean rates all become more discrepant).

\section{DISCUSSION}

The major findings of this study are the variability of overall rates for suicide ideation and the general consistency of these rates for suicide attempts across cross national sites with the low rate of suicide attempts in Beirut and Taiwan. Approximately $10-18 \%$ of the population across diverse countries report suicidal ideation and 3-5\% have made a suicide attempt at some time in their life. Females and divorced or separated persons are at high risk. The welldocumented increased risk for completed suicide in men, as compared to women, and the closer sex ratios for suicidal ideation than attempts suggest that the risk as reflected in ideation is similar between the sexes but that the outcome differs.

The wide increase in suicidal ideation and slight increase in suicide attempt in the United States reported between 1980 and 1990 even when the samples are restricted to the identical age ranges is of interest. While identical questions were asked in the 1980 and 1990 surveys, the 1990 survey used more meticulous 
probing into which resulted in higher rates of most disorders. Thus, the apparent increase maybe due to methodological differences between studies.

Our findings parallel findings from other studies. In a study using hospital morbidity data from Adelaide and Perth in Australia (Davis \& Kosky, 1991), the rates for attempted suicide in men increased $47 \%$ between $1971-2$ and 1986-7 and decreased $9 \%$ for females during the same period, tending to reduce the size of the female to male ratio between these two time periods from $2 \cdot 3$ to $1 \cdot 4$. Similarly, we found an increase in suicide attempts between the 1980 and 1990 surveys in the United States and a decrease in the sex ratios.

Data from the western part of the Netherlands (Arensman et al. 1995) showed that the mean annual incidence of medically treated suicide attempts, data monitored from general hospitals, psychiatric hospitals and primary-care physicians were 95/100000 for males and 155/100000 for females (with a female to ratio of 1.6) during the period between 1989 and 1993, a sex ratio slightly lower than the NCS (2.02) conducted during the same time period.

The suicide attempt rate (per 100000) in the city of Oxford, England declined slightly from 330 in 1989 to 301 in 1992 (Hawton et al. 1994). The mean incidence of suicide attempts (per 100000 ) for the years 1989-1993 was 186 for females and 140 for males in Sor-Trondelag, Norway $($ ratio $=1 \cdot 3) \quad($ Hjelmeland \& Tjerke, 1996). Both the Oxford and Sor-Trondelag studies based on treated samples show the decreasing female to male ratio in suicide attempts and rates at a later date than when most of the cross-national studies were conducted, corresponding to that trend we see in the 1990s in the US from the National Comorbidity Study. Nevertheless, there is a suggestion that the rates of suicide attempts in continental Europe have decreased slightly from 1989 to 1992 (Schmidtke et al. 1996).

A 1969 community survey conducted in New Haven, Connecticut, was the forerunner of the ECA, which had New Haven as one of its sites also assessed suicidal feelings and attempts. Two questions on suicide feelings were included: 'Have you ever thought of taking your life even if you would not really do it?' and 'Have you ever reached the point where you seriously considered taking your life or perhaps made plans how you would go about doing it?'. These questions are similar in intent to the DIS question 'Did you ever feel so low you thought of committing suicide?'. The lifetime prevalence of suicide feeling in the New Haven 1969 survey, in answer to these two suicidal questions 4.8 and $2 \cdot 6 / 1000$ respectively or $7 \cdot 4 \%$, which is lower than the $11 \cdot 18 \%$ in the 1980 ECA survey or the $16.52 \%$ in the 1990 NCS survey. Furthermore, the lifetime suicide attempt rate based on similar questions in the 1969 New Haven survey and the later ECA surveys was also considerably lower, $1 \cdot 1 / 1000$ in New Haven 1969 in contrasted to $3 \cdot 1 / 100$ in 1980 and $4 \cdot 8 / 100$ in 1990 (Paykel et al. 1974).

The lower rates of suicide ideation and attempt in Taiwan are of interest. Suicide ideation and attempt are three to four times as high in Korea as in Taiwan although both are Asian industrialized nations. However, the rates of most psychiatric disorders were found to be lower in Taiwan, which may be due to cultural differences in willingness to admit to symptoms.

Beirut, a city that had been afflicted by war at the time of the survey has the lowest rates of suicide ideation and attempts of all the countries studied. However, separate analyses show that Beirut has one of the highest rates of major depression (Weissman et al. 1996) and an increase in rates in the cohort born after 1945 (Cross National Collaborative Group, 1992). These results must be viewed cautiously, because of the small size of the sample studied in Beirut $(N=435)$.

The higher rates of suicide ideation and attempts in the separated/divorced parallels findings for the risk for major depression in these countries (Weissman et al. 1996) and also findings on an increase in mortality from other causes for persons who are divorced or separated compared to those married (Berkman \& Breslow, 1983). Interestingly, in Puerto Rico the rates for suicide ideation and attempts did not vary markedly by marital status. Bravo et al. (1991) has shown that Puerto Ricans living in Puerto Rico have an average of five persons who are frequently consulted in their social network. Their high level of family and other social support may buffer the effects of divorce and separation.

There are limitations to these data. We lack 
data on age and time of ideation, attempts or separation or divorce and cannot, therefore, separate out the extent to which separation or divorce is the cause or the consequence of the suicidal ideation or attempt. Gender and marital status were studied although a host of other demographic risk factors might explain the variation in rates. Controlling for confounding by other psychiatric disorders and marital status explains some, but not all of the differences in rates for suicide ideation and attempts between the sites. In addition, these are retrospective reports and probably underestimate the rates due to forgetting or subject reluctance to acknowledge the behaviour. Finally, while these studies were all directed and carried out and the instruments were translated by investigators from the individual countries, it is possible that cultural differences in the understanding of the questions could have affected the rates. In summary, suicide attempts are a substantial problem in diverse countries with some variations in rates, probably due to cultural features that we do not as yet understand.

These cross-national analyses were supported by the National Institute of Mental Health (Program Project Grant MH37592 and Mental Health Research Center Grant 30906-12).

\section{REFERENCES}

American Psychiatric Association, Committee on Nomenclature and Statistics (1980). Diagnostic and Statistical Manual of Mental Disorders, 3rd edn. American Psychiatric Association: Washington, DC.

American Psychiatric Association, Committee on Nomenclature and Statistics (1987). Diagnostic and Statistical Manual of Mental Disorders, 3rd edn., revised. American Psychiatric Association: Washington, DC.

Andrews, J. A. \& Lewinsohn, P. M. (1992). Suicidal attempts among older adolescents: prevalence and co-occurrence with psychiatric disorders. Journal of the American Academy of Child and Adolescent Psychiatry 31, 655-662.

Arensman, E., Kerkhof, A. J. F. M., Hengeveld, M. W. \& Mulder, J. D. (1995). Medically treated suicide attempts: a four year monitoring study of the epidemiology in The Netherlands. Journal of Epidemiology and Community Health 49, 285-289.

Berkman, L. F. \& Breslow, L. (1983). Health and Ways of Living The Alameda County Study. Oxford University Press: New York.

Bland, R. C., Orn, H. \& Newman, S. C. (1988). Lifetime prevalence of psychiatric disorders in Edmonton. Acta Psychiatrica Scandinavica 77 (suppl. 338), 24-32.

Bravo, M., Canino, G., Rubio-Stipec, M. \& Woodbury, M. (1991). Importancia de la familia como recurso de apoyo social en Puerto Rico (Importance of the family as a resource in social support in Puerto Rico). Puerto Rico Health Sciences 5, 140-156.

Breslow, N. E. \& Day, N. E. (1987). Statistical Methods in Cancer Research. Volume II. The Design and Analysis of Cohort Studies. International Agency for Research on Cancer: Lyon.
Bronisch, T. \& Wittchen, H. U. (1994). Suicidal ideation and suicide attempts: comorbidity with depression, anxiety disorders, and substance abuse disorders. European Archives of Psychiatry and Clinical Neuroscience 244, 93-98.

Canetto, S. S. \& Lester, D. (1995). Gender and the primary prevention of suicide mortality. Suicide and Life Threatening Behaviors 25, $58-69$.

Canino, G. J., Bird, H. R., Shrout, P. E., Rubio-Stipec, M., Bravo, M., Martinez, R., Sesman, M. \& Guevara, L. M. (1987). The prevalence of specific psychiatric disorders in Puerto Rico. Archives of General Psychiatry 44, 727-735.

Cantor, C. H., Leenaars, A. A., Lester, D., Slater, P. J., Wolanowski, A. M. \& O'Toole, B. (1996). Suicide trends in eight predominantly English-speaking countries 1960-1989. Social Psychiatry and Psychiatric Epidemiology 31, 364-373.

Cross-National Collaborative Group (1992). The changing rate of major depression: cross-national comparisons. Journal of the American Medical Association 268, 3098-3105.

Davis, A. T. \& Kosky, R. J. (1991). Attempted suicide in Adelaide and Perth: changing rates for male and females, 1971-1987. Medical Journal of Australia 154, 666-670.

Dubow, E. F., Kausch, D. F., Blum, M. C., Reed, J. \& Bush, E. (1989). Correlates of suicide ideation and attempts in a community sample of junior high and high school students. Journal of Clinical Child Psychology 18, 158-166.

Dyck, R. J., Bland, R. C., Newman, S. C. \& Orn, H. (1988). Suicide attempts and psychiatric disorder in Edmonton. Acta Psychiatrica Scandinavica 77 (suppl. 338), 64-71.

Faravelli, C., Degl'Innocenti, B. G., Aiazzi, L., Incerpi, G. \& Pallanti, S. (1989). Epidemiology of anxiety disorder in Florence. Journal of Affective Disorders 19, 1-5.

Harkavy-Friedman, J. M. H., Asnis, G. M., Boeck, M. \& DiFiore, J. (1987). Prevalence of specific suicidal behaviors in a high school sample. American Journal of Psychiatry 144, 1203-1206.

Hawton, K., Fagg, J., Simkin, S. \& Mills, J. (1994). The epidemiology of attempted suicide in the Oxford area, England (1989-1992). Crisis, 15, 123-135.

Hjelmeland, H. \& Tjerke, T. (1996). Parasuicide in the county of SorTrondelag, Norway. General epidemiology and psychological factors. Social Psychiatry and Psychiatric Epidemiology 31, $272-283$.

Hwu, H. G., Yeh, E. K. \& Chang, L. Y. (1989). Prevalence of psychiatric disorders in Taiwan defined by the Chinese diagnostic interview schedule. Acta Psychiatrica Scandinavica 79, 136-147.

Karam, E. (1992). Depression et guerres du Liban: méthodologie d'une recherche. Annales de Psychologie et des Sciences de l'Education pp. 99-106. Université St. Joseph: Beyrouth.

Kessler, R. C., McGonagle, K. A., Zhao, S., Nelson, C. B., Hughes, M., Eshleman, S., Wittchen, H. U. \& Kendler, K. S. (1994). Lifetime and 12-month prevalence of DSM-III-R psychiatric disorders in the United States. Results from the National Comorbidity Survey. Archives of General Psychiatry 51, 8-19.

Lee, C. K., Kwak, Y. S., Yamamoto, J., Rhee, H., Kim, Y. S., Han, J. H., Choi, J. O. \& Lee, Y. H. (1990a). Psychiatric epidemiology in Korea. Part I: Gender and age differences in Seoul. Journal of Nervous and Mental Disease 178, 242-246.

Lee, C. K., Kwak, Y. S., Yamamoto, J., Rhee, H., Kim, Y. S., Han, J. H., Choi, J. O. \& Lee, Y. H. (1990 b). Psychiatric epidemiology in Korea. Part II: Urban and rural differences in Seoul. Journal of Nervous and Mental Disease 178, 247-252.

Lepine, J. P., Lellouch, J., Lovell, A., Teherani, M., Ha, C., VerdierTaillefer, M. H., Rambourg, N. \& Lemperiere, T. (1989). Anxiety and depressive disorders in a French population: methodology and preliminary results. Psychiatry and Psychobiology 4, 267-274.

Lester, D. (1994). The epidemiology of suicide in Chinese populations in six regions of the world. Chinese Journal of Mental Health 7, 25-36.

Lewis, S. A., Johnson, J., Cohen, P., Garcia, M. \& Valez, C. N. (1988). Attempted suicide in youth: its relationship to school achievement, educational goals, and socioeconomic status. Journal of Abnormal Child Psychology 16, 469-471. 
Madianos, M. G., Madianou-Gefou, D. \& Stafanis, C. N. (1993). Changes in suicidal behavior among nation-wide general population samples across Greece. European Archives of Psychiatry and Clinical Neuroscience 243, 171-178.

Moscicke, E., O'Carroll, P., Rae, D. S., Lock, B. Z., Roy, A. \& Regier, D. A. (1988). Suicide attempts in the Epidemiologic Catchment Area Study. Yale Journal Biology and Medicine 61, 259-268.

Oakley-Browne, M. A., Joyce, P. R., Wells, J. E., Bushnell, J. A. \& Hornblow, A. R. (1989). Christchurch psychiatric epidemiology study. Part II: Six month and other period prevalence for specific psychiatric disorders. Australian and New Zealand Journal of Psychiatry 23, 327-340.

Orn, H., Newman, S. C. \& Bland, R. C. (1988). Design and field methods of the Edmonton survey of psychiatric disorders. Acta Psychiatrica Scandinavica 77 (suppl. 338), 17-23.

Paykel, E. S., Myers, J. K., Lindenthal, J. J. \& Tanner, J. (1974) Suicidal feelings in the general population: a prevalence study. British Journal of Psychiatry 124, 460-469.

Platt, S., Bille-Brahe, U., Kerkhof, A., Schmidtke, A., Bjerke, T. Crepet, P., DeLeo, D., Haring, C., Lonnqvist, J., Michel, K. Philippe, A., Pommereau, X., Querejeta, I., Salander-Renberg, E., Temesvary, B., Wasserman, D. \& Sampaio-Faria, J. (1992) Parasuicide in Europe: the WHO/EURO multicentre study on parasuicide. I. Introduction and preliminary analysis for 1989. Acta Psychiatrica Scandinavica 85, 97-104.

Potthoff, R. F., Woodbury, M. A. \& Manton, K. G. (1992) 'Equivalent sample size' and 'equivalent degrees of freedom' refinements for inference using survey weights under superpopulation models. Journal of the American Statistical Association 87, 383-396.

Prichard, C. (1996). New patterns of suicide by age and gender in the United Kingdom, and the Western world 1974-1992: an indicator of social change? Social Psychiatry and Psychiatric Epidemiology 31, 227-234.

Robins, L. N. \& Regier, D. A. (eds.) (1991). Psychiatric Disorders in America: The Epidemiologic Catchment Area Study. The Free Press: New York.

Robins, L. N., Helzer, J. E. \& Croughan, J. L. (1981). The NIMH diagnostic interview schedule: its history, characteristics, and validity. Archives of General Psychiatry 38, 381-389.

Robins, L. N., Orvaschel, H., Anthony, J., Blazer, D., Burnam, A. \&
Burke, J. (1985). The diagnostic interview schedule. In Epidemiologic Field Methods in Psychiatry: The NIMH Epidemiologic Catchment Area Program (ed. W. W. Eaton and L. G. Kessler), pp. 143-170. Academic Press: Orlando, FL.

Sartorius, N. (1995). Recent changes in suicide rates in selected eastern European and other European countries. International Psychogeriatrics 7, 301-308.

Schmidtke, A., Bille-Brahe, U., DeLep, D., Kerkhof, A., Bjerke, T., Creper, P., Haring, C., Hawton, K., Lonnqvist, J., Michel, K., Pommereau, X., Querejeta, I., Phillips, I., Salander-Renberg, E., Temesvary, B., Wasserman, D., Fricke, S., Weinacker, B. \& Sampaio-Faria, J. G. (1996). Attempted suicide in Europe: rates, trends and sociodemographic characteristics of suicide attempters during the period 1989-1992. Results of the WHO/EURO Multicenter Study on Parasuicide. Acta Psychiatrica Scandinavica 93, 3278-3338.

Smith, K. \& Crawford, S. (1986). Suicidal behavior among normal high school students. Suicide and Life Threatening Behavior 16, 313-325.

US Department of Health and Human Services (1992). National Health Interview Survey: 1989. National Center for Health Statistics: Hyattsville, MD.

Weissman, M. M., Bland, R., Canino, G., Faravelli, C., Greenwald, S., Hwu, H. G., Joyce, P. R., Karam, E. G., Lee, C. K., Lellouch, J., Lepine, J. P., Newman, S. Rubio-Stipec, M., Wells, J. E., Wickramaratne, P., Wittchen, H. U. \& Yeh, E. K. (1996). Crossnational epidemiology of major depression and bipolar disorder. Journal of the American Medical Association 276, 293-299.

Wells, J. E., Bushnell, J. A., Hornblow, A. R., Joyce, P. R. \& Oakley-Browne, M. A. (1989). Christchurch psychiatric epidemiology study. Part I: Methodology and lifetime prevalence for specific psychiatric disorders. Australian and New Zealand Journal of Psychiatry 23, 315-326.

Wittchen, H. U., Essau, C. A., von Zerssen, D., Krieg, J. C. \& Zaudig, M. (1992). Lifetime and six-month prevalence of mental disorders in the Munich Follow-up study. European Archives of Psychiatry and Clinical Neuroscience 241, 247-258.

World Health Organization (1990). Composite International Diagnostic Interview (CIDI). Version 1.0. World Health Organization: Geneva.

Yip, P. S. (1996). Suicides in Hong Kong, Taiwan and Beijing. British Journal of Psychiatry 169, 495-500. 